\title{
Entrevista com Ronald Grele: consideraçóes sobre história oral
}

\section{Interview with Ronald Grele: reflections on oral history Entrevista con Ronald Grele: consideraciones sobre historia oral}

\author{
Valéria Barbosa de Magalhães ${ }^{1 *}$ \\ ${ }^{1}$ Universidade de São Paulo, São Paulo/SP - Brasil
}

\section{Apresentaçáo}

Ronald Grele é um senhor gentil, de fala suave, que nasceu em Connecticut, em 1934. É pai de quatro filhos adultos e reside hoje em Nova York, nos arredores da Universidade de Colúmbia. Sob a simpatia de quem generosamente recebe pesquisadores em sua casa, está um dos maiores nomes da história oral mundial e um dos mais experientes conhecedores de entrevistas de história pública.

Grele é atualmente diretor emérito (aposentado) do Centro de História Oral da Universidade de Colúmbia (Columbia University Oral History Research Office). Foi diretor do Programa de História Oral da Universidade da Califórnia (Oral History Program at UCLA). Coordenou projetos com história oral em outras instituiçóes de renome: New Jersey Historical Commission, Ford Foundation Oral History Project e John F. Kennedy Oral History Project. Foi presidente da Associação Americana de História Oral, na gestão de 1988. Dentre suas principais publicaçóes, estão: Envelops of sound (1975) e Multiculturalism and subjectivity in oral history: an international anthology (1972).

A relevância do trabalho de Grele para a história oral tem sido reconhecida, nos Estados Unidos e fora dele, por nomes como Mary Marshall Clark, Luisa Passerini e Alessandro Portelli. Desde o início de sua carreira na área, ele produziu reflexóes sobre o processo de produção e tratamento de entrevistas e dos arquivos.

DOI: http://dx.doi.org/10.1590/2237-101X02104501

Entrevista recebida em 7 de abril de 2020 e aceita para publicação em 11 de junho de 2020.

* Professora da Universidade de São Paulo / Escola de Artes, Ciências e Humanidades, São Paulo/SP - Brasil.

E-mail: gephom@gmail.com. ORCID: https://orcid.org/0000-0002-6817-4192.

Entrevista realizada por Valéria Barbosa de Magalhães em 3 de fevereiro de 2019, em Nova York, no âmbito do projeto de pesquisa Nordestinos em São Paulo e história oral: abordagem histórico-crítica, financiado pela Fapesp e coordenado pela entrevistadora. Transcrição: Aline dos Campos Reis (Bolsista TT/Fapesp). Conferência e tradução: Valéria B. Magalhães. 
No tocante ao processo de análise de entrevistas, aproximou-se do estruturalismo, no início de sua carreira, inspirado particularmente na obra de Louis Althusser. Grele se preocupava também com a relação entre história e ideologia, avançando depois para a análise interpretativa. Sua obra tentou responder aos dilemas da interação entre sujeito e eventos históricos, entre memória e história.

É um pesquisador voltado à prática da entrevista, mas também um teórico da história oral, ainda que negue tal alcunha. Uma parte de suas principais publicaçôes voltou-se à discussão da produção e análise da fonte oral, tendo influenciado geraçôes de pesquisadores pelo mundo. Dentre suas contribuiçóes teóricas, destaca-se uma abordagem interpretativista da entrevista para entender suas estruturas mais profundas. Grele trouxe da linguística para a história oral o termo conversational narrative (ou narrativa conversacional ${ }^{2}$ ) visando compreender como são construídas, na interação de uma entrevista, as narrativas sobre o passado.

Para ele, o entrevistado não seria simplesmente uma fonte informacional de pesquisa, mas integraria o próprio processo de análise. Essa interação entre entrevistador e entrevistado traria à tona o confronto de perspectivas que existe entre eles. $\mathrm{O}$ historiador seria o responsável por fornecer uma estrutura analítica que permitiria ao entrevistado ir a fundo em sua descrição de eventos vividos, criando juntos uma explicação mais profunda e rica sobre o passado. A conversaçáo seria um ato intersubjetivo em que os dois lados explorariam suas diferenças e semelhanças.

Sua trajetória profissional o conduziu, quase que naturalmente, a essas reflexôes e ao interesse pela história oral, como será possível ler nesta entrevista. Na fala de abertura que proferiu na sessão em sua homenagem, intitulada "The work of Ronald J. Grele: a lifetime of contributions to oral history”, em 2016, no Meeting of the Oral History Association, por ocasiáo do 50 aniversário da associação, Grele assim explicou seu interesse pelas histórias de vida:

Quando me perguntam sobre como entrei na história oral e por que nela fiquei, costumo responder, brincando mas com tom de seriedade, que entrei porque suspeitava que, em algum lugar, havia pessoas que levavam vidas muito mais interessantes do que a minha. E fiquei porque descobri que isso era verdade 3 (GRELE, 2019; p. 183-190).

\footnotetext{
${ }^{2}$ As narrativas conversacionais, para os estudos de linguística e sociologia, visam ao entendimento do papel do contato social no rumo que uma história segue. Desse ponto de vista, as histórias seriam construídas no contato social e na interação oral (no caso da história oral, entre entrevistador e entrevistado). Narrativas conversacionais são, portanto, formas de se criar e de se manter relaçóes, de compartilhar e se entender socialmente os acontecimentos do passado por meio da reelaboraçáo da memória. Para um melhor entendimento do conceito, ver, por exemplo, Norrick (2000), Bastos (2004) e Norrick (2005).

3 Tradução minha. No original: "When people ask me how I got into oral history, and why I continued, I usually tell them, jokingly but with a tinge of seriousness, that I got into oral history because I had the sneaking suspicion that somewhere there were people who led far more interesting lives than I did; I stayed because I found out that this was true".
} 
Essa generosidade com as histórias, com os entrevistados, o seu genuíno interesse pelas vidas dos outros e pela forma como cada um interpreta os acontecimentos de seu passado, estão refletidos em sua produção teórica e metodológica sobre história oral.

Na sessão em sua homenagem no Meeting of the Oral History Association de 2016, Grele disse ser um historiador que faz entrevistas e que está interessado em entender como as pessoas constroem suas histórias, não se considerando um teórico, ainda que seja visto como tal por diversos pesquisadores da história oral.

Dentre as inúmeras ligaçôes com nomes importantes da história oral, Ronald Grele manteve uma frutífera amizade intelectual com Luisa Passerini durante vários anos. Os dois discutiram e desenvolveram ponderaçôes acerca da centralidade do sujeito na história oral e elaboraram críticas sobre certa politização em voga do papel do historiador, que estaria em detrimento do debate sobre as fontes. Eles também foram responsáveis por importantes colóquios epistemológicos no combate ao positivismo na História e em favor das fontes orais.

Grele conheceu nomes fundadores da história oral brasileira, tais como Marieta de Moraes, Antônio Montenegro e José Carlos Sebe Bom Meihy, e também intelectuais internacionais, a exemplo de Alessandro Portelli, de quem, nesta entrevista, mostrou-se um admirador. Participou dos mais importantes encontros internacionais de história oral no mundo, sendo uma memória viva da constituição desse campo.

Ouvir o que Grele tinha a dizer foi como extrapolar os limites de uma entrevista, foi de fato uma aula. Dela, destaco quatro pontos que considero relevantes para qualquer pesquisador que trabalhe com história oral:

- A trajetória de Grele como pesquisador e a forma como seu percurso profissional de mais de 50 anos moldou o seu entendimento sobre história oral;

- Sua explicação sobre as duas vertentes orientadoras do trabalho com história oral: a antropológica e a hermenêutica;

- A mudança, nos últimos anos, de uma história oral mais voltada às questóes do mundo do trabalho para uma orientaçáo mais culturalista e subjetivista;

- Sua visão sobre a discussão de ética em história oral: o debate estaria hoje mais voltado a aspectos pessoais da relação entrevistador-entrevistado, do que propriamente metodológicos.

Grele oferece aqui um panorama de sua carreira e de como a trajetória profissional acarretou o seu envolvimento com a história oral, nos mostrando (e ensinando) que a constituição de um sólido percurso e o aprendizado acadêmico vêm da experiência mais braçal no dia a dia: a de ouvir várias vezes uma entrevista, de transcrever e de conferir gravaçóes de outros entrevistadores.

Gostaria, por fim, de agradecer a Ronald Grele por ter me recebido tâo gentilmente em sua residência e também pelas indicaçôes de instituiçôes de história oral americanas para o 
meu projeto. E, é claro, pela cessão desta bela entrevista. Foi fascinante vê-lo, naquela etapa da vida, tão lúcido e intelectualmente vívido. A escuta de sua incrível experiência nas diversas instituiçôes de pesquisa dos Estados Unidos foi inspiradora. Grele é um apaixonado pelas histórias e pela vida.

Ao sair de sua casa, e quando meu gravador já estava desligado, Grele pediu: "por favor, leve meu abraço a todos aqueles amigos brasileiros que conheci nos encontros de história oral e que, provavelmente, nunca mais verei".

\section{Entrevista}

Valéria Magalhấes: Obrigada pela entrevista. Hoje é dia 3 de fevereiro de 2019. A primeira coisa que eu gostaria de perguntar seria sobre sua experiência pessoal com a história oral. Quando foi que o senhor se deu conta de que ela seria um bom caminho para suas pesquisas?

Ronald Grele: Há muito tempo, lá por 1964 ou 1965. Estava procurando um trabalho e um amigo meu, que era ex-diretor do Departamento de História onde eu trabalhava e onde era estudante de pós-graduação, me chamou. Eu tinha ido para Washington D.C. e ele era o editor da American Historical Review.

Eu estava no Lafayette College por um ano, mas era só na escola de verão, e já tinha quatro filhos. Ele me ligou por volta de agosto e disse: "terei um trabalho em setembro, você ainda está procurando emprego?” Eu disse que sim. Então, ele falou com um amigo que era arquivista da Roseville Library e estava coordenando um projeto de história oral sobre John Kennedy, que havia sido assassinado há um ou três anos. Eu estava interessado em pegar esse trabalho, mas disse: "o que é história oral?" (risos).

VALÉRIa MagalHães: O senhor nunca tinha tido contato com a história oral?

Ronald Grele: Nunca. Então, ele disse: "não se preocupe, você vai aprender". Aí fui para Washington e fui entrevistado pelo diretor do departamento, Charles Morrissey ${ }^{4}$. Ele me contratou. Trabalhei por um ano na Kennedy Library e gostei enormemente do trabalho. Eu

\footnotetext{
${ }^{4}$ Charles T. Morrissey foi um dos pioneiros da história oral nos Estados Unidos (e no mundo) e um dos fundadores da American Oral History Association. Foi editor do International Journal of Oral History, entre os anos 1950 e 1980. Publicou inúmeros artigos e livros sobre história oral e trabalhou na constituiçấo de vários acervos americanos importantes, começando, nos anos 1940, com o registro da história de congressistas do Governo Harry Truman. Subsequentemente, foi trabalhar como diretor do arquivo John Kennedy. Charlie, como é chamado, foi consultor de história oral por mais de 40 anos, tendo formado diversos profissionais da área, tanto no campo acadêmico, quanto de história pública.
} 
não gostava de trabalhar para os Kennedy, mas gostava da Kennedy Library. Era uma situação difícil porque muitas das pessoas antigas da Kennedy tinham empregos nos arquivos, mais difícil para o Charlie, obviamente. Mas trabalhei lá por um ano e entáo fui dar aulas na Califórnia, onde não iria trabalhar com história oral, mas nessa minha primeira experiência fiz 40 ou 50 entrevistas. As pessoas sempre me perguntam sobre essas entrevistas, eu nunca quis falar sobre isso, tinha minhas ressalvas, mas ao escrever minhas memórias, tenho juntado algumas que terminei há muito tempo. Estou procurando em meu computador e só tenho essas, acho que daqui a um ano poderei falar sobre elas.

VAlÉRia Magalhâes: O senhor organizou isso como um arquivo pessoal de entrevistas?

Ronald Grele: Sim, das entrevistas que tenho feito. Depois da Kennedy Library e dessas entrevistas, fui dar aulas na Califórnia. Quando eu estava lá, no meu primeiro ano, Charles Morrissey ia para uma conferência na Califórnia organizada pela Oral History Association. Ele tentou me convencer a ir, mas eu não queria, tinha minhas ressalvas em relação à história oral.

Após alguns anos, fiquei na Califórnia por dois ou três anos e voltei para a Costa Leste para terminar minha dissertaçáo. Eu lecionava em uma faculdade no Brooklyn com um contrato de dois anos e precisava de outro trabalho. Minha mulher estava na escola de biblioteconomia escrevendo sobre arquivos de história oral e me pediu uma bibliografia, mas eu não estava familiarizado com o campo e disse: "ligue para o Chalie porque sei que ele está familiarizado com esse tema". Ela ligou, perguntou o que precisava e depois conversei um pouco com ele. Ele disse: "volte de Nova York"! Charlie tinha assinado um contrato com a Ford Foundation para fazer a história oral da fundação. Desligamos. Após dez minutos, ele ligou novamente e disse: "sabe o que pensei? Por que você não vem como diretor-assistente?" Eu estava procurando um emprego (eu sempre estava precisando de emprego). Então, ajudei novamente o Charlie, trabalhando com ele por mais três anos.

Achava que eu ficaria na Ford Foundation entrevistando gente, mas na maior parte do tempo eu trabalhei nos arquivos, contratando pessoas, supervisionando os transcritores. Naquele tempo sem computadores, era um longo e tedioso processo, tinha que revisar as transcriçôes. Conto um pouco disso na segunda edição de Envelopes of sound (GRELE, 1975; GRELE, 1990). A forma como aprendi história oral de fato foi com o trabalho do dia a dia, ouvindo muitas entrevistas, inúmeras vezes. Charlie fazia as entrevistas, fiz algumas, mas ele realizava a maioria. Trazia, eu ouvia e o transcritor fazia a maior parte das transcriçóes. Eu ia de novo e: "vamos ouvir novamente para ter certeza". Se tivesse algo incorreto, voltava para a pessoa ouvir e fazer as correçóes. Aí vinha para mim e eu editava para o datilógrafo. E ele fazia a edição e conferia e assim por diante. Eu ouvia cada uma das entrevistas duas ou três vezes e lia as transcriçôes. 
Algo acontece com você quando está táo intensamente envolvido em tantas entrevistas. Algumas tinham 20 ou 30 horas de duraçáo, alguma coisa tem que acontecer com você. Aí eu comecei a ficar interessado em história oral. Estava ouvindo tantas entrevistas, algo aconteceu. Daí evoluiu o ensaio que escrevi, Envelopes of sound, que terminei em 1972, mas a primeira edição saiu em 1975 e a segunda em 1985.

Depois da Ford Foundation, também fiz entrevistas para minha dissertação, que foi sobre a história de Nova Jersey, de uma organização política local. Entrevistei pessoas que eram politicamente ativas naquela organizaçáo. No final das contas, fiz história oral pela Ford Foundation e era consultor do Gutman ${ }^{5}$, no projeto sobre classe trabalhadora e etnias na cidade de Nova York, estava fazendo as duas coisas. Aí fui para a Indonésia pelo Fullbright Program, por um ano. Voltei e fui trabalhar para o New Jersey Historical Commission com história pública. Lá, fiz um pequeno número de entrevistas com lideranças, mas na maior parte do tempo eu viajava por Nova Jersey convencendo as pessoas de que elas deveriam fazer história oral, concedendo bolsas e ajudando em projetos. Há 30 ou 40 projetos em todo o estado de Nova Jersey. Fizemos vários trabalhos com as comunidades afro-americanas, com a classe trabalhadora, com todo mundo que você possa imaginar: pessoas ricas, classe média alta etc. Nos tentávamos abarcar muito da classe trabalhadora e da história étnica.

Um dos projetos conseguiu muito dinheiro para fazer história étnica. Fizemos 2.500 entrevistas. Essa é uma coleção muito grande, tem quase todas as etnias de Nova Jersey. Acho que todas essas entrevistas estão no Rutgers New York. Acho que o Jack Tchen ${ }^{6}$ trouxe as entrevistas. Fizemos muitos trabalhos em Nova Jersey quando saí da UCLA. Aí eu me envolvi em um movimento internacional, naquele momento, entre a Historical Commission e a UCLA. Por volta de 1982 ou 1983, eu vim para a Colúmbia. Fiquei aqui por 19 anos e depois me aposentei.

Valéria Magalhães: E aí, então, o senhor foi trabalhar em Colúmbia como diretor do Center for Oral History Research?

RONALD GRELE: Isso, foi como diretor.

VAlÉRIa Magalhâes: Como o senhor vê a história oral hoje? Como história pública? Método?

Ronald Grele: Bem, quando eu cheguei - tendo em conta que o Center for Oral History Research foi criado em 1948 - ele era uma coleção que estava em desenvolvimento, era mais

\footnotetext{
${ }^{5}$ Herbert George Gutman foi professor de História na CUNY (City University of New York) e coordenou o projeto American Social History Project, financiado pela NEH e Ford Foundation, que visava documentar a história da classe trabalhadora em Nova York.

${ }^{6}$ John Kuo Wei Tchen, mais conhecido como Jack Tchen, é professor da Rutgers University e cofundador do Museum of Chinese in America e do New York Newark Public History Project (NYN PHP).
} 
como uma parte de um arquivo e a ideia era entrevistar pessoas que tinham feito história. Eu lembro que era um acervo muito grande. Já havia uma coleção considerável e eles tinham tido dois diretores antes de mim: Allan Nevins ${ }^{7}$ e Louis Starr ${ }^{8}$. Continuei com esse desenvolvimento do acervo, essa era minha atividade principal. Nós também fizemos muita história pública, fizemos muitos projetos de organização de outros acervos da cidade de Nova York. Fizemos muito treinamento e orientação. Eu digo "nós", mas éramos eu e mais duas pessoas, havia outras, mas era eu que fazia isso.

Iniciei uma série de seminários em Colúmbia para os quais eu trouxe colegas meus da Europa, alguns da Ásia e Estados Unidos. Tivemos uma grande conferência internacional de história oral sobre história das mulheres, em 1983. Fizemos vários trabalhos com o Museum of Chinese in America (MOCA), fizemos muitos trabalhos com o Puerto Rican Center, muita coisa sobre história afro-americana, isso com várias agências norte-americanas, durante mais de 20 anos.

VALÉRIa MagalHâes: É uma grande experiência!

Ronald Grele: É sim. Pouco tempo atrás, alguns amigos, a Linda Shopes e a Rina Benmayor, organizaram um encontro da American History Association em homenagem a mim', foi uma coisa pequena e modesta.

VALÉRIA Magalhães: Que incrível!

RonAld GRelE: Havia três pessoas perguntando na mesa e aí eu respondia. Eles transformaram em algo mais e vão publicar parte disso na Oral History Review ${ }^{10}$. Será no próximo número.

Esqueci completamente por que eu me lembrei disso... ah, sim, tinha a ver com minha carreira, é uma menção à minha carreira.

\footnotetext{
${ }^{7}$ Allan Nevins é considerado o pioneiro da formação de acervos de história oral nos Estados Unidos, começando nos anos 1940, na Universidade de Colúmbia. Fez sua primeira entrevista em 1948, tendo criado, logo em seguida, o Columbia Oral History Research Office, atual Columbia Center for Oral History (CCOH), que conta hoje com um dos maiores arquivos de entrevistas do mundo.

${ }^{8}$ Louis Starr sucedeu Allan Nevins como diretor do Columbia Oral History Research Office, após sua aposentadoria, em 1956. Historiador, foi também professor do Departamento de Jornalismo da Columbia University.

'Sessão "The work of Ronald J. Grele: a lifetime of contributions to oral history", no encontro anual da Oral History Association Traditions, Transitions and Technologies from the Field, por celebração dos 50 anos da instituição. Long Beach, California, 12 a 16 de outubro de 2016. Da sessão, participaram: Luisa Passerini, Alexandre Freund, Jack Tchen, Mary Marshall Clark e Andor Skotnes.

${ }^{10}$ The Contributions of Ronald J. Grele to Oral History. The Oral History Review, v. 46, n. 1, 2019. Disponível em: https://www.tandfonline.com/toc/uohr20/46/1?nav=tocList\& . Acesso em 7 fev. 2019.
} 
VALÉRIA MAgalhães: Isso mostra o quanto o seu trabalho é importante para a história oral.

Ronald Grele: Sim. Luisa Passerini foi uma dos presentes, Mary Marshall Clark, Jack Tchen e muitos dos meus ex-estudantes. Isso tudo será publicado.

VAlÉRIa Magalhães: Espero poder ver essa publicação.

Ronald Grele: Sim, mas não sei se será publicado no Brasil.

Valéria Magalhâes: Podemos comprar online, será muito importante para nós. Eu posso pedir para a biblioteca da universidade comprar.

RonAld GRele: Eles provavelmente poderão adquirir.

Valéria Magalhâes: Sim! Gostaria também de perguntar como o senhor vê o fato de a American Oral History Association ter sua própria orientação de ética em pesquisa, pois no Brasil enfrentamos essa questáo recentemente, dos comitês de ética em pesquisa solicitarem que nossos projetos sejam submetidos ao seu escrutínio, ainda que suas orientaçôes sejam da área de Saúde.

Ronald Grele: Você provavelmente conhece, qual o nome dele? Santhiago ${ }^{11}$ ? Eu assisti à sua apresentação em Atlanta, quando foi ao Encontro da Oral History Association. Naquela ocasião, ele levantou a questão da ética e disse que, no Brasil, a discussão sobre ética seria um modo de evitar o enfrentamento de problemas metodológicos ${ }^{12}$. Eu pensei muito sobre aquilo. E quanto mais eu penso, mais acho que há algo importante ali. Eu não sei bem por que, tenho suposiçóes, mas uma das questôes centrais da história oral nos Estados Unidos é uma preocupação real com a ética e essa tem sido uma inquietação que não vem de hoje. Estive envolvido com a associação por muitos anos, estive no Conselho da associação mais tempo do que qualquer pessoa e fui presidente por um período. Voltando um pouco, lá pelos anos 1960, quando eu me envolvi pela primeira vez (não me lembro onde eu trabalhava, mas devia ser na Ford Foundation), eu me envolvi porque fiz parte da conferência inicial sobre ética em história oral, que foi organizada pelo meu antecessor em Colúmbia, Louis Starr. Eu não estava trabalhando em Colúmbia, mas em algum outro lugar, foi quando a história oral

\footnotetext{
${ }^{11}$ Aqui, Grele faz referência à apresentação de Ricardo Santhiago, em 2010, no Encontro de História Oral da Oral History Association.

${ }^{12}$ Grele antecipou essa reflexão em sua fala de abertura no 2016 Meeting of the Oral History Association, na mesa em sua homenagem. Para ele, a história oral teria passado a conviver com certo sentimentalismo que, apesar de tornar a entrevista um espaço mais seguro e confortável, teria um efeito danoso por fazer as histórias, especialmente as mais difíceis, se perderem nesse caminho mais caloroso (GRELE, 2019; p. 183-190).
} 
começou a ser muito popular entre um grupo de pessoas que se autodenominavam "historiadores públicos" e que estavam oferecendo história oral por dinheiro. Então, Louis conseguiu um financiamento da National Endowment for the Humanities (NEH) e organizou o que veio a se tornar Wingspread Conference ${ }^{13}$, em julho de 1979, que aconteceu no Frank Lloyd Wright's Building, em Wisconsin. Durou quatro ou cinco dias e fiz parte dela. Éramos 25 pessoas e basicamente trabalhamos nos objetivos e orientaçóes da Oral History Association. Por causa das ligaçóes do Louis com a NEH, essas orientaçóes se tornaram parte de suas exigências. Se você quisesse conseguir um financiamento da NEH, você teria que obedecer às regras da Oral History Association, algo em torno de três a cinco páginas muito bem elaboradas. Mas o objetivo, é claro, era garantir que aquelas pessoas nunca obtivessem fundos ou bolsas, a não ser que fizessem história oral do jeito do Louis. Minha análise é cautelosa, mas eu acho que o Louis estava muito preocupado com aqueles forasteiros. Era um jeito de garantir que, ou eles se tornariam insiders, ou não fariam história oral e não conseguiriam nenhum dinheiro da NEH. E todo mundo quer financiamento da NEH.

VAlÉRIa Magalhâes: Então, dificultaria para essas pessoas que queriam ganhar dinheiro com história oral?

RonAld Grele: Sim. Louis já faleceu, mas estava muito preocupado com isso e ele era uma figura muito poderosa dentro da sua área profissional e também da história oral. Eu lembro que tínhamos muitas conferências e então um dos objetivos foi fazer o regulamento da Oral History Association.

Em algum momento dos anos 1980, houve outra grande conferência da qual eu participei. Esta foi mais acadêmica e algumas das pessoas envolvidas, que me lembre, eram Joel Gardner $^{14}$ e Don Ritchie ${ }^{15}$. Essa foi mais séria e mais elaborada, lidando com questôes como o anonimato e muitas outras mais espinhosas e com os problemas éticos.

Há alguns anos, eles revisaram tudo isso, inclusive o Michael Frisch ${ }^{16}$ estava presente. Mas, naquela época, minha impressão é de que a história oral tinha se tornado tão popular, tâo generalizada em todos os lugares, com milhôes de estilos, que não havia mais razão para uma batalha ética. Mesmo assim, eles trabalharam nisso. $\mathrm{Na}$ última versão, eles trabalharam no que vinha sendo pensado na Oral History Association, em termos da preocupação ética no sentido mais pessoal. Muitas pessoas que fazem entrevistas estão

${ }^{13}$ Wingspread Conference. Racine, Wisconsin, 27 a 28 jul. 1979.

${ }^{14}$ Joel Gardner foi membro do conselho da American Oral History Association e publicou artigos e livros sobre história oral.

${ }^{15}$ Donald Richie foi historiador do Senado Americano, tendo conduzido projetos de história oral para esse órgão desde 1976. Autor de livros sobre história oral, foi presidente da American Oral History Association e da International Oral History Association.

${ }^{16}$ Michael Frisch foi editor da Oral History Review, entre 1986 e 1997. É professor emérito do Departamento de História da Universidade de Buffalo, tendo escrito textos importantes sobre história oral e história pública. 
mais interessadas na história social como um tipo de terapia, como "medicina narrativa"17. Ao lidar com a pobreza, com pessoas acometidas pelo álcool, por exemplo, ou gays, a história oral estava se expandindo para comunidades nas quais não tinha estado antes. Muitas dessas comunidades náo eram necessariamente da classe trabalhadora ou de grupos étnicos, eram comunidades muito maiores. Aí os problemas éticos se tornaram problemas pessoais. Como lidar com isso? Se observarmos as três regras do Wingspread, ${ }^{18}$ duas são mais acadêmicas e a terceira é mais sobre as transformaçôes da ideia americana sobre ética. Essa última me atinge, eu fui contra ela, não concordei. Primeiramente, porque náo era necessária e era muito restritiva para o campo: pesquisadores tão preocupados se deveriam ser gentis! Era esse o ponto do texto de Santhiago: havia algo ali. Se acontece na Associação Brasileira de História Oral, está acontecendo na Associação Americana também. Estaria se tornando um problema pessoal como forma de evitar as questôes das diferenças metodológicas. É uma questão de evitar homens entrevistando mulheres ou as diferenças de classe. Isso se tornou um ponto de natureza muito diferente da época em que eu comecei. Mas são problemas metodológicos, não éticos. Eles podem até se tornar pessoais, mas, primeiramente, se você é um historiador, então é um problema metodológico. Então, os comentários dele ressoaram em mim, naquele momento, e uma vez que comecei a trabalhar nisso, me tornei mais e mais linha dura a esse respeito e mais crítico em relação às entrevistas muito "terapêuticas" e à "medicina narrativa".

Por outras razôes, não posso entrar em detalhes aqui, mas acho que as pessoas estão se confundindo. No final das contas, elas se sentem bem com isso. A questão não é se o entrevistador se sente bem ou não com isso, mas sim se ele cumpriu seu trabalho. Você precisa estar preocupado em fazer um bom trabalho, não necessariamente em ser uma boa pessoa. Há três ou quatro sujeitos da Oral History Association, que dedicaram suas vidas à associação, que estấo mais preocupados em serem boas pessoas.

Mary Marshall ${ }^{19}$, por exemplo, está muito mais antenada com o método terapêutico, em alcançar as pessoas, e ela é muito boa nisso. É metodológico. Ela trabalhou com vítimas do 11 de Setembro e há, em seu livro, entrevistas realmente maravilhosas, ela é uma pessoa muito conversadora. $\mathrm{Na}$ minha abordagem, sempre houve um pouco mais de distanciamento, pois somos pessoas diferentes, é explicável. Ela é uma pessoa mais acessível.

\footnotetext{
${ }^{17}$ Aqui, Grele se refere ao risco de confusão entre a entrevista de história oral e a narrativa terapêutica, em alusão à crescente discussão de setores das Humanidades sobre o conceito de "medicina narrativa", ligado às práticas de humanização da medicina que se valem das narrativas como forma de mais respeito ao outro e em contraposição à progressiva burocratização das práticas médicas. Para entender melhor o conceito de medicina narrativa, ver, por exemplo, Charon, 2006.

${ }^{18}$ As regras do Wingspread podem ser encontradas na publicação: Oral History Evaluation Guidelines: the Wingspread Conference. The Oral History Review, n. 8, p. 6-19, 1980.

${ }^{19}$ Mary Marshall Clark é a atual diretora do Columbia Center for Oral History e é também codiretora e fundadora do Columbia Oral History Master of Arts.
} 
VAléria Magalhâes: Vejo então que essas discussōes sobre ética em história oral não são um problema só no Brasil.

Ronald GRele: Não, estão em todo lugar. O controle dos comitês de ética não funciona. Isso até é uma coisa que quero falar com a Mary Marshall porque, nos Estados Unidos, há uma tentativa de reativar os comitês de ética, já de longa data. Ela estava bem envolvida nisso quando foi presidente da associaçáo, como esteve envolvida em outros temas também. A história oral tem uma isenção nos Estados Unidos.

Valéria Magalhães: E eu acho que no Brasil também deveria ter.

Ronald Grele: Você poderia conversar com a Mary Marshall sobre isso. Concordo com você: o Brasil deveria ter isso. Não sei em que bases conseguimos, mas é algo no sentido de argumentar que a história oral não é uma ferramenta de pesquisa permanente ou algo assim. Ela poderia explicar melhor.

VALÉRIa Magalhães: Esta é uma briga política na história oral, pois se não afirmarmos que o trabalho com história oral tem certas especificidades com as quais temos que lidar e que os profissionais da área de Saúde não estáo aptos a avaliar, não conseguiremos resolver isso.

Ronald GRele: Isso. A diferença é antiga, de quando eu ainda era aluno de pós-graduação, isto é, a História está preocupada com o indivíduo e a sua singularidade. Acho que a história oral é como a profissão da História: é a especificidade. É uma distinção que eu não faria agora, mas que era feita nos anos 1940 e 1950, quando eu era estudante. De qualquer forma, a história oral tem uma isenção nos Estados Unidos, uma isenção dos comitês de ética.

Valéria Magalhães: Entendo a história oral como um método usado nas Ciências Humanas (talvez isso seja um pouco diferente para o seu uso como história pública), que talvez não se adeque às regras da área de Saúde.

Ronald Grele: A forma como eu a descreveria, o modo com que fazemos pesquisa de campo, é que há duas abordagens. Uma é a etnográfica e a outra é a hermenêutica. A abordagem etnográfica está preocupada com o que realmente aconteceu: "o que aconteceu? Blá, blá, blá... me conte”. $\mathrm{Na}$ abordagem hermenêutica, busca-se interpretar os significados do acontecimento. E fazemos as duas: estamos preocupados com o que aconteceu e com os significados: "O que é importante? O que você selecionou? Como você cria sua própria história de um certo jeito?” Fazemos os dois e é assim que eu veria o trabalho do Portelli: como uma síntese. Ele não explica assim porque não é um historiador, mas é assim que os historiadores 
veem. Eu não gosto dessa distinção que eles fazem sobre a pesquisa, pois entendo pesquisa como algo que envolve muito mais que isso. Mas está tudo bem porque, de qualquer forma, não estou mais trabalhando com isso (risos).

VAléria Magalhâes: Minha última questão seria: como o senhor vê o papel da história oral para os estudos migratórios e para outros temas diversos?

Ronald Grele: Bem, estou nisso há muito tempo e quando comecei, lá atrás, na pulsação dos anos 1960, nós estávamos realmente preocupados em trazer a classe trabalhadora para a História, trazer os outsiders de volta para a História, de mostrar que a história da classe trabalhadora era tão honrada quanto qualquer outra, blá, blá, blá. E nós acabamos nos movendo daquela concepção social que envolvia a classe trabalhadora para uma concepção muito mais cultural, que não está somente documentando sua participação no trabalho e na História em andamento, mas também documentando a cultura, o que eles estão trazendo para a experiência e para sua trajetória de vida. Hoje, é sobre todos os tipos de questóes biográficas e assuntos. É uma abordagem mais cultural e mais biográfica. Estamos mais preocupados com a família, com a existência orgânica. Nós falamos, falamos, falamos... (risos). Isso é mais orgânico, mais expandido hoje.

Sobre o papel específico da história oral eu não estou certo, porque, nos Estados Unidos pelo menos, ela emergiu em um tempo quando todos os tipos de política estavam efervescendo. Estavam emergindo no folclore, em particular, na cultura material, nos estudos da cultura material, dos objetos da classe trabalhadora. Um amigo meu diria: "como podemos entender a cultura do ex?" Você olha para isso e tenta entender como foi usado ao longo dos séculos. Como era usado? Você constrói uma concepção cultural das pessoas. Isso aconteceu no folclore. $\mathrm{Na}$ antropologia foi de tal forma que quase naufragou a disciplina, sabia? Mas a história oral era parte disso, parte do exercício geral de expansão do mundo em que vivemos. Não é que a história oral seja mais importante que outras, ela só é parte de todo um processo de como entendemos o mundo em que vivemos.

A história oral tem coisas únicas, mostramos isso tempos atrás, em especial o Louis. Nós temos a ideia de que o historiador analisa o produto daquilo que ele mesmo criou. Isso é algo a se prestar atenção: o período em que as pessoas produziram cultura material, elas estão criando o ex, eles estudam o ex. Fizemos isso! Ele não existe, exceto para nós. E aí o analisamos como se ele existisse sem nós, mas não. Então, é única nesse sentido. Mas esse é um problema que não foi discutido de fato em todas as disciplinas de entrevistas.

Essas questôes aparecem de maneiras diferentes em coisas que tenho lido recentemente, mas que são problemas antigos. Estou lendo um ensaio de uma antropóloga de Irvine, não precisamos entrar em detalhes sobre ela, que está preocupada com a forma com que a conversação se torna parte do processo de trabalho. Não necessariamente o que é dito, mas o dizer que 
envolve a construção de uma rede etc. Ela cita Malinowski, nos anos 1930, mas se ela fosse mais para trás, no início do Business Management, quando eles fizeram o Hawthorne Study, descobririam que o comportamento dos trabalhadores mudava só de serem entrevistados. Eles queriam criar um espírito de trabalho, então entrevistaram pessoas sobre isso. Portanto, é um problema de longa data que surgiu de maneira diferente em seu ensaio. São velhas questôes nesse campo. Muita coisa que se lê, se pensarmos cuidadosamente mais para trás, você verá que são questôes antigas.

Recentemente, li um livro sobre o passado "audível" (STERNE, 2003), isto é, sobre gravar o passado, as vozes do passado. Quando as pessoas fizeram as primeiras gravações, lá no século XIX ${ }^{20}$, uma das primeiras foi para preservar as vozes dos mortos. É um livro maravilhoso. A questáo do embalsamamento, da preservação em recipientes, de preservar comida, os aspectos da preservaçáo... E você está preservando o passado como voz, as vozes do passado. Isso surgiu ao mesmo tempo da emergência dos museus como empresas profissionais para preservação. Mas são velhos problemas, isso volta atrás em muito tempo. Toda a ideia de preservação emerge quando você vai em algum lugar e eles querem preservar as vozes das pessoas. Não estão preocupados com o que aconteceu, querem ter a voz do marido para preservá-la para os filhos.

Então, tem um tipo de aspecto de preservação que precisa ser investigado como parte do que fazemos. E, é claro, é uma parte muito importante em termos da preocupação sobre a evolução de uma ideologia. É muito importante.

Valéria Magalhâes: Para além do significado do que foi dito...

Ronald Grele: Em entrevistas com pessoas que se identificam como italianas, a terceira e a quarta geração de italianos, eles diziam serem italianos, mas na Itália não seriam nem um pouco italianos. Eles dizem a você que são italianos. Há um livro maravilhoso sobre uma conferência entre ítalo-americanos e italianos, era uma conferência enorme organizada pela Italian American Historical Association. A ideia era mostrar que eles eram todos a mesma coisa, mas todas as apresentaçôes mostravam que eram duas culturas totalmente diferentes, não têm nada a ver uns com os outros (risos). Nada a ver! Mas é importante para os ítalo-americanos considerarem a si mesmos como tais. Mas por quê? Por que, se eles não são? Por que as pessoas lidam com isso? É algo ilógico. Não é mais uma questão da etnografia, é algo mais, é interpretativo. Exceto na primeira leva de italianos, não há nada sobre como eles realmente viviam. Eles vivem como ítalo-americanos. Precisamos de novos termos para entendermos isso.

${ }^{20}$ No ano de 1860. 
Valéria Magalhâes: Temos algo parecido no Brasil. Temos vários descendentes de italianos lá, mas especialmente com os japoneses, os nipo-brasileiros, quando vão para o Japáo nesse fluxo migratório chamado decasségui. No Brasil, eles são vistos e se imaginam como japoneses, mas quando chegam no Japão, se dão conta de que lá não são reconhecidos como tais.

Ronald Grele: Nem um pouco, nem um pouco. Quando eu ensinava na Califórnia, tinha um projeto, acho que financiado pela Ford Foundation, que levou seis estudantes afro-americanos para a Nigéria a fim de descobrirem suas raízes. Bem, os jovens saíram de São Francisco e de Los Angeles, quando voltaram, perceberam que...

\section{VAlÉRIA Magalhães: Não eram africanos?}

Ronald GRele: Eles voltaram com um interesse novo em serem somente de São Francisco ou de Los Angeles. As pessoas que eles encontraram lá sabiam que eles não eram africanos, o modo que andavam, falavam... tudo neles!

É isso. Posso ajudar em algo mais?

Valéria Magalhães: Acho que é só. Agradeço imensamente pela entrevista e pela gentileza em me receber em sua casa.

\section{Referências}

BASTOS, Liliana Cabral. Narrativa e vida cotidiana. Scripta, v. 8, n. 14, p. 118-127, 18 mar. 2004.

CHARON, Rita. Narrative medicine: honoring the stories of illness. New York: Oxford University Press, 2006.

GRELE, Ronald J. Comment. The Oral History Review, v. 46, n. 1, p. 183-190, 2019. Disponível em: https://doi.org/10.1093/ohr/ohy062. Acesso em 26 fev. 2020.

GRELE, Ronald. Envelopes of sound: six practitioners discuss the theory, method, and practice of oral history. Chicago: Precedent, 1975.

GRELE, Ronald. Envelopes of sound: the art of oral history. 2. ed. Chicago: Precendent Publishing, 1990.

NORRICK, Neal R. Conversational narrative: storytelling in everyday talk. Amsterdam: John Benjamins, 2000.

NORRICK, Neal R. Interactional remembering in conversational narrative. Journal of Pragmatics. v. 37, n. 11, 2005. 
ORAL History Evaluation Guidelines: the Wingspread Conference. The Oral History Review, n. 8, p. 6-19, 1980.

SANTHIAGO, Ricardo. Each one on its own square, or Please don't talk about ethics: some unaccountable misconceptions of (a certain) oral history in Brazil. Oral History Association 44th Annual Meeting. Atlanta: OHA, 2010.

STERNE, Jonathan. The audible past: cultural origins of sound reproduction. Duke University Press, 2003.

THE Contributions of Ronald J. Grele to Oral History. The Oral History Review, v. 46, n. 1, 2019. Disponível em: https://www.tandfonline.com/toc/uohr20/46/1?nav=tocList\&. Acesso em 7 fev. 2019. 